\title{
Editorial
}

\section{A consensus statement on relative merits of EEG and MEG}

\author{
European Concerted Action on Biomagnetism, Lyon Meeting, November 26 and 27, 1991
}

\begin{abstract}
G Anogıanakıs (Thessalonıkı), J M Badıer (Rennes), G Barrett (London), S Erné (Berlın), R Fenıcı (Rome), P Fenwıck (London), F Grandorı (Mllan), R Harı (Helsınkı), R Ilmonıemı (Helsinkl), F Mauguıère (Lyon), D Lehmann (Zurich) F Perrın (Lyon), M Peters (Enschede), G-L Romanı (Chietı), P M Rossını (Rome)
\end{abstract}

\section{Foreword from the Editor}

\begin{abstract}
Controversies belong to scientists' occupational therapy Editors are delighted to promote such war games in which they act as referees As an alternative means to clarify controversial 1ssues, a consensus meetıng can be better adapted to address hot questions such as whether, and eventually how, MEG should be promoted as a tool for investigating human brain functions This was the opinion shared by members of the expert group on biomagnetism who met in Lyon in November 1991 with the support of the European Community (COMAC-BME Concerted Action on Biomagnetism) This group included scientists from eight European countries workıng with MEG or EEG who, after two days of meetıng and several weeks of "faxıng," succeeded in producing this consensus statement emphasising the arguments on the relative merits of the two methods, which any clinical neurophysiologist should be aware of
\end{abstract}

Françoıs Mauguière

Some controversy has arisen recently regarding the source localization accuracy of EEG and MEG The discussion was triggered by the study of Cohen et al (1990) who created test sources in the brain by feeding current into depth electrodes implanted in epileptic patients The magnetic and electric fields produced by the artificial dipoles were obtained in 16 simultaneous EEG and 16 successive 1-channel MEG recordings The sources were determined with an $8 \mathrm{~mm}$ average error for MEG and a $10 \mathrm{~mm}$ error for EEG localızation This study has been criticized on methodological grounds in recent letters to the editor of Annals of Neurology (Harı et al 1991, Willamson 1991)

Since public discussion is continuing on the relative merits of EEG and MEG in the study of human brain functions (Crease 1991), we as European scientists working with EEG and MEG consider it necessary to summarize our experience on the topic The following discussion focuses on dipole-lıke sources, $1 \mathrm{e}$, to generators of small volumic extent

Correspondence to F Mauguière, Editor-in-Chıef of "EEG and Clinical Neurophysiology," Neurological Hospital, 59 Boulevard Pinel, 69003 Lyon (France)

\section{Differences and simılarities of EEG and MEG}

The strongest contributions to both EEG and MEG come from postsynaptic currents flowing in neurons, located mainly in the cerebral cortex for MEG and in the whole brain for EEG MEG is most sensitive to activity in fissural cortex, where the source currents flow tangentıally to the surface of the head EEG receives contributions from both radial and tangential currents and is also relatively more sensitive than MEG to deep sources

In the case of tangential dipoles, MEG best discerns changes in the locations of the source along the fissural cortex, whereas EEG's best sensitivity for location is along the orientation of the dipole Concentric inhomogeneities do not affect the magnetic field Because of the almost spherical shape of the skull, the magnetic field pattern outside the head is thus easier to analyze than the electric potential distribution on the scalp However, recent improvements in scalp current density methodology have clarified interpretation of EEG data significantly

If the conductivities of all tissues were exactly known, the locating accuracy for a single dipole within a spherical model in the absence of notse would be about one-third better for MEG than for EEG In reality, the 
exact resistivities are not known, and thus the relative accuracy of EEG is decreased The source location accuracy of both methods depends on the signal-tonoise ratio and on the adequacy of source and volume conductor models and is best for superficial sources

As no electrodes are needed for MEG recordings, the preparation time for a MEG mapping is very short, and no problems similar to the variations in electrode resistıvitıes, electrode-skın interface or electrode polarization are encountered In addition, DC-coupled MEG recordıngs are possible

During MEG recordings the subject has to stay immobile Therefore, MEG cannot be used to measure activity during motor seizures with major motor symptoms or in incooperative subjects Moreover, MEG cannot be used in electronically noisy environments (intensive-care units, operatıng rooms, etc )

MEG recordings have led to important achievements in source localization In practice, one of the most important differences between EEG and MEG recordings is encountered in the case of concurrently active multıple sources, MEG's selectıvity to tangential currents and the more localized field patterns significantly facilitate data interpretation Examples include successful differentiation between activities of the first and second somatosensory areas SI and SII, detection of new aspects of spontaneous brain rhythms, and detection of selective activation in subareas of SI

EEG's dbility to detect both tangentral and radial sources and new spatio-temporal analysis methods have yielded interesting results as well Examples include successful differentiation between tangential and radial sources for cortical auditory and somatosensory evoked potentials and identification of radial sources in the frontal areas for some cognitive evoked potentials

The differences between EEG and MEG explain, for example, the discovery of different aspects of the tonotopic organization of the human auditory cortex with the two methods

\section{Clinical aspects}

In epilepsy, the aim of neurophysiological recordings is to help the surgeon to make talored and conservative resections During preoperative evaluation, MEG should be used in combination with other methods, including metabolic studies Epileptic focı can be located with respect to cortical sulci on the basis of evoked response studies Mapping the results onto a 3-dimensional MRI reconstruction would help the surgeon to orient on the surface of the brain after opening of the skull

Determination of interhemispheric differences in source parameters, including their strengths, may be efficient in the studies of both normal physiology and pathology and can also be used in the follow-up of focal lesions and of plastic reorganization of cortical functions This type of analysis should be undertaken with both EEG and MEG techniques

\section{Minimum requirements to obtain a real comparison of EEG and MEG}

The level of absolute accuracy of both EEG and MEG source determination is at present a somewhat open question The studies have been based either on simulations and theoretical calculations, or on experiments with technical deficiencies The experiment to solve this question should be fair to both methods, including comparable experımental set-ups, adequate number of channels for both, proper models, etc Unfortunately, these requirements have not been met so far

For example, when studyıng artıfıcıal dipoles in the brain, the depth electrodes should have such contact surfaces that they form (tangential) dipoles not exceeding 3-5 $\mathrm{mm}$ in length The drilling holes should be small and sealed with an insulator to decrease leakage of volume currents Furthermore, the current flow should not be changed by plastic plates containıng, e $\mathrm{g}$, subdural electrodes The measurement grids should cover the whole field patterns The real locations of the sources and sensors should be determined convincingly It is important to note that in multichannel MEG instruments the exact location of each sensor is known in advance with respect to all others

Simultaneous depth-electrode recordings could be used to find out to what extent the depth spikes are reflected in MEG and in the scalp EEG

\section{Complementanty of $M E G$ and $E E G$}

EEG and MEG are complementary, both are useful in studies of normal and pathological human brain functions Their combination may allow (1) identification of the number of distinct (tangential as well as radial) active brain areas, (11) determination of tangential and radial components of current dipoles, and (111) distınction between cortical and deep sources

Education of new clinical neurophysiologists about the fundamentals of EEG and MEG will help them to think in terms of sources and brain activity rather than in terms of graphoelements To prevent unfruitful overlap, the literature of both EEG and MEG studies should be familiar to both groups of investigators

\section{Conclusions}

More cooperation between the EEG and MEG communities is needed In this "decade of the brain," EEG and MEG are the only non-1nvasive methods 
with millisecond temporal resolution for studying the functions of the human brain More realistic source models should be considered and in this case new criteria for EEG vs MEG comparison in terms of spatial resolution will have to be defined

New multıchannel magnetometers have made MEG recordings clinically feasible and the price of MEG instrumentation per channel is decreasing Any neuroscience center interested in studies of higher brain functions at this level of analysis would benefit from combining both methods, with state-of-the-art instruments for both This means that multi-sensor devices are needed for MEG and up-to-date analysis is required for both kinds of data Funding should be targeted so that neuroscience research institutes and hospitals can have high-quality instruments for funda- mental brain research, studies of cognitive processes, and valıdıty testıng of clinical applicatıons

\section{References}

Cohen, D, Cuffın, B, Yunokuchı, K, Manıewskı, R, Purcell, C, Rees Cosgrove, G, Ives, J, Kennedy, J and Schomer, D MEG versus EEG localization test using implanted sources in the human brain Ann Neurol, 1990, 28 811-817

Crease, R P Images of conflict MEG vs EEG Science, 1991, 253 374-375

Harı, R, Hamalainen, M, Ilmonıemı, R and Loundsmaa, O V MEG versus EEG localization test Letter to the Editor Ann Neurol, $199130222-223$

Willamson, S MEG versus EEG localization test Letter to the Editor Ann Neurol, 1991, 30222 